\title{
A PRÁTICA COMO COMPONENTE CURRICULAR NA DISCIPLINA PESQUISA E PROCESSOS EDUCATIVOS DO CURSO DE PEDAGOGIA: UM DIFERENCIAL NA RELAÇÃO ENTRE PESQUISA, TEORIA E PRÁTICA
}

\author{
BRANDT, Andressa Graziele (Brasil, Santa Catarina, Camboriú) ${ }^{1 *}$; \\ HOBOLD, Márcia de Souza (Brasil, Santa Catarina, Florianópolis) ${ }^{2^{* *}}$ \\ ${ }^{1}$ Instituto Federal de Educação, Ciência e Tecnologia Catarinense \\ ${ }^{2}$ Universidade Federal de Santa Catarina \\ ORCID ID: https://orcid.org/0000-0002-8176-1930* \\ ORCID ID: https://orcid.org/0000-0002-4179-608X
}

\begin{abstract}
RESUMO
Este artigo discute o papel da Prática como Componente Curricular nos processos iniciais de formação de professores, tendo como objetivo central analisar a proposta de formação dos licenciandos de um curso mediante exame das disciplinas de Pesquisa e Processos Educativos, as quais consubstanciam a Prática como Componente Curricular. Nesta pesquisa qualitativa, o tratamento dos dados baseou-se na análise de conteúdo proposta por Bardin (2009), por André (2012, 2017) e por Gatti e Barreto (2009) acerca do papel da pesquisa na formação dos professores e pelas contribuições de García $(1999,2009)$ acerca do desenvolvimento profissional. Os resultados indicaram que a Prática como Componente Curricular, associada aos aprendizados das práticas formativas da docência, tendo a pesquisa como eixo de verticalização da formação de professores, é fundamental para o desenvolvimento profissional dos futuros professores, tornando-se elemento essencial para o desenvolvimento da habilidade investigativa e contribuindo para a sua formação profissional, artística, científica e política.
\end{abstract}

PALAVRAS-CHAVE

Formação inicial de professores. Prática de ensino. Pesquisa.

THE PRACTICE AS A CURRICULAR COMPONENT IN THE DISCIPLINE RESEARCH AND EDUCATIONAL PROCESSES OF THE PEDAGOGY

COURSE: A DIFFERENTIAL IN THE RELATIONSHIP BETWEEN RESEARCH, THEORY AND PRACTICE

\begin{abstract}
This article discusses the role of Practice as a Curricular Component in the initial processes of teacher training, whose main objective is to analyze the proposal of the training of the graduates of a course by examining the disciplines of Research and Educational Processes, which consubstantiate the Practice as a Curricular Component. In this qualitative research, the data treatment was based on the content analysis proposed by Bardin (2009), by André $(2012,2017)$, and by Gatti and Barreto (2009) on the role of research in teacher training, and by the contributions of García $(1999,2009)$ on professional development. The results indicated that the Practice as a Curricular Component, associated to the learning
\end{abstract}

Educação \& Formação, Fortaleza, v. 4, n. 11, p. 142-160 maio/ago. 2019

DOI: https://doi.org/10.25053/redufor.v4i11.319

http://seer.uece.br/redufor 
practices of teaching, having the research as a vertical axis of teacher training, is fundamental for the professional development of the future teachers, becoming an essential element for the development of the research skills contributing to their professional, artistic, scientific and political training.

\title{
KEYWORDS
}

Initial teacher training. Teaching practice. Search.

\section{LA PRÁCTICA COMO COMPONENTE CURRICULAR EN LA DISCIPLINA INVESTIGACIÓN Y PROCEDIMIENTOS EDUCATIVOS DEL CURSO DE PEDAGOGÍA: UN DIFERENCIAL EN LA RELACIÓN ENTRE INVESTIGACIÓN, TEORÍA Y PRÁCTICA}

\begin{abstract}
RESUMEN
Este artículo discute el papel de la Práctica como Componente Curricular en los procesos iniciales de formación de profesores, tiene como objetivo central analizar la propuesta de formación de los licenciandos de un curso mediante el examen de las disciplinas de Investigación y Procesos Educativos, las cuales consubstancian la Práctica como Componente Curricular. En esta investigación cualitativa, el tratamiento de los datos se basó en el análisis de contenido propuesto por Bardin (2009), por André $(2012,2017)$ y por Gatti y Barreto (2009) acerca del papel de la investigación en la formación de los profesores y por las contribuciones de García (1999, 2009) sobre el desarrollo profesional. Los resultados indicaron que la Práctica como Componente Curricular, asociada a los aprendizajes de las prácticas formativas de la docencia, teniendo la investigación como eje de verticalización de la formación de profesores, es fundamental para el desarrollo profesional de los futuros profesores, convirtiéndose en un elemento esencial para el desarrollo de la habilidad investigativa y contribuyendo a su formación profesional, artística, científica y política.
\end{abstract}

PALABRAS CLAVE

Formación inicial de profesores. Práctica de enseñanza. Investigación.

\section{INTRODUÇÃO}

Este artigo tem como foco de estudo o Currículo do Curso de Pedagogia (CPe) ofertado no Instituto Federal Catarinense (IFC), campus Camboriú, que teve início em 2011, observando e discutindo o que dispõe o respectivo Projeto Pedagógico de Curso (PPC) em relação às disciplinas denominadas Pesquisa e Processos Educativos (PPE), que contêm em suas cargas horárias as Práticas como Componentes Curriculares (PCC). 
Destaca-se que os Pareceres do Conselho Nacional de Educação - Câmara Plena (CNE/CP) n. 28 e n. 9, de 2001, que fundamentaram as Resoluções CNE/CP n. 1 e 2, de 2002, discutem a PCC no contexto da formação de professores da Educação Básica. Nesses documentos, tanto a prática como o estágio são momentos para trabalhar a reflexão sobre a atividade profissional.

A Resolução CNE/CP n. 2, de 2002, determina que a PCC e o estágio são momentos destinados ao trabalho de reflexão sobre a atividade profissional, entretanto a prática não deve limitar-se a um espaço isolado, tampouco ser reduzida ao estágio (BRASIL, 2002a, 2002b).

A PCC propõe atividades pedagógicas que buscam estabelecer relação entre teoria, prática e pesquisa por meio de atividades de integralização do currículo e de proposições de seus conteúdos ao longo de todo o itinerário formativo do $\mathrm{CPe}$, com vistas à formação de professores para os anos iniciais do Ensino Fundamental, Educação Infantil e gestão, tendo como base a docência.

As discussões sobre a formação de professores nos cursos de licenciatura dos Institutos Federais (IFs) são de suma importância, visto que analisam o planejamento do PPC realizado pelos docentes dessa instituição de ensino e, consequentemente, os processos de ensino-aprendizagem e de formação pedagógica desenvolvidos com os discentes, elementos fundantes para a formação desses profissionais, que atuarão na Educação Infantil, nos anos iniciais do Ensino Fundamental e na gestão, em espaços escolares e não escolares.

Contudo, não podemos deixar de elucidar que o processo de formação inicial de professores vigente na Educação Profissional Tecnológica (EPT), apesar dos nove anos de existência dos IFs, apresenta-se como um contexto novo, aumentando a responsabilidade dessas instituições de ensino, as quais, ao oferecer os $\mathrm{CPe}$, ou seja, a formação de professores para a Educação Básica, mediante seus cursos de licenciatura, tornam-se parceiras e incentivadoras da constituição da docência nos espaços coletivos e colaborativos.

Destacamos que o CPe pesquisado possui o documento Normatização da Prática como Componente Curricular, que regulamenta e define normas e critérios para a PCC no âmbito das práticas pedagógicas do curso, e Regulamento da disciplina de

Educação \& Formação, Fortaleza, v. 4, n. 11, p. 142-160 maio/ago. 2019 
Pesquisa e Processos Educativos e Trabalho de Curso, ambos fontes documentais do estudo que serão discutidas e analisadas no presente texto.

Nessa direção, organizamos o texto em quatro seções, além da Introdução, a saber: i) a experiência formativa da PCC como espaço para o desenvolvimento profissional do futuro professor; ii) o percurso metodológico da pesquisa; iii) as disciplinas de pesquisa e processos educativos e sua inter-relação com a PCC; e iv) as Considerações Finais. Dessa maneira, a seguir apresentamos as análises desenvolvidas referentes às fontes documentais selecionadas para a pesquisa.

\section{PRÁTICA COMO COMPONENTE CURRICULAR COMO ESPAÇO PARA O DESENVOLVIMENTO PROFISSIONAL: EXPERIÊNCIA FORMATIVA}

Compreende-se, após exame da legislação educacional (Parecer CNE/CP n. 9/2001; Resolução CNE/CP n. 2/2002; e Resolução CNE/CP n. 2/2015) e do documento do $\mathrm{CPe}$ Normatização da Prática como Componente Curricular (IFC CAMBORIÚ, 2017a), que a finalidade da PCC é construir conhecimentos relacionados aos campos de atuação profissional do pedagogo por meio das diversas atividades formativas que compõem o $\mathrm{CPe}$, operacionalizada como parte das disciplinas ou como projetos integradores, aproximando teoria e prática à formação pedagógica dos acadêmicos.

Para Oliveira e Brito (2017), a PCC faz parte do núcleo das disciplinas de conteúdos pedagógicos e específicos, como uma subdivisão das disciplinas obrigatórias para a licenciatura. Dessa forma, sua origem, os seus objetivos do projeto e suas proposições de prática de ensino têm importante contribuição na formação inicial docente, ressaltando que a carga horária é um espaço-tempo privilegiado para acontecer à articulação da teoria com a prática de maneira integrada e interdisciplinar. Nessa perspectiva, segundo as autoras, cabe "[...] ao professor formador dar a devida importância e deixar claro como está trabalhando e como os alunos podem vivenciar esse espaço" (OLIVEIRA; BRITO, 2017, p. 92).

Destaca-se a obrigatoriedade de cumprir 400 horas de PCC, distribuídas ao longo de todo o processo formativo, conforme a Resolução CNE/CP n. 2/2015, que define as Diretrizes Curriculares Nacionais para a formação inicial em nível superior 
(cursos de licenciatura, cursos de formação pedagógica para graduados e cursos de segunda licenciatura) e para a formação continuada. Nas novas Diretrizes Curriculares Nacionais (DCNs), de 2015, a prática reflexiva baseada em uma das ações que integram a Política Nacional de Formação de Professores, que podem ser aprovadas em breve, como o Programa de Residência Pedagógica, "[...] precisa, sim, de teorias educacionais, ou se corre o risco de voltar algumas décadas, da qual talvez nunca se tenha saído totalmente, quando se acreditava que ensinar é dom e que se aprende a partir da vivência" (PEREIRA; MOHR, 2017, p. 207).

Compreende-se, portanto, que as teorias da área das Ciências da Educação tornam-se importantes frente a esses limites para auxiliar os professores na compreensão da complexidade da docência e dos diversos aspectos que a envolvem, dentro e além da sala de aula. Além disso, "[...] enquanto as atividades de PCC vincularem-se apenas a ideias formuladas a partir da experiência docente dos professores, pode-se reforçar a ideia de que ensinar aprende-se fazendo" (PEREIRA; MOHR, 2017, p. 207).

Conforme 0 artigo 20 do referido Regulamento (IFC CAMBORIÚ, 2017a), o componente curricular Pesquisa e Processos Educativos tem como objetivos a formação com pesquisa, bem como a inserção, desde o processo inicial de formação, nos campos de atuação profissional. Procura desenvolver a capacidade investigativa e produtiva do estudante e contribuir para a sua formação básica, profissional, artística, científica e política, o que, na nossa análise, traz contributos à formação inicial do professor e do pedagogo.

De acordo com o proposto pelas DCNCLPe de 2006, a organização do currículo do $\mathrm{CPe}$ contempla um desenvolvimento curricular pensado para dar conta dessa proposta multidimensional. Conforme afirma Scheibe (2003), na organização dos tempos e conteúdos, tendo em vista atender à exigência de 200 dias letivos anuais, com 4 horas de atividades diárias, em média, é desejável que a duração de um curso de licenciatura seja de 4 anos, com um mínimo de 3.200 horas, para que seja possível contemplar, de forma mais aprofundada, tanto a carga teórica necessária à formação como o desenvolvimento das Práticas como Componentes Curriculares, que aproximam 0 estudante da realidade social e profissional.

Educação \& Formação, Fortaleza, v. 4, n. 11, p. 142-160 maio/ago. 2019 
Nesse sentido, compreende-se que:

\begin{abstract}
A PCC é uma prática que deve produzir algo no âmbito do ensino e pode ser entendida como uma ferramenta para a problematização e a teorização de questões pertinentes ao campo da educação e à área de ensino, oriundas do contato direto e/ou indireto com o espaço escolar e educacional e com o espaço das vivências e experiências acadêmicas ou profissionalizantes; e ainda como uma possibilidade para viabilizar a integração entre os diferentes aportes teóricos que compõem a investigação científica e os campos de conhecimento em educação e ensino. (TORRES; SILVÉRIO; MAESTRELLI, 2017, p. 217).
\end{abstract}

Consoante o documento Normatização da Prática como Componente Curricular (IFC CAMBORIÚ, 2017a), a PCC será desenvolvida por meio de: observação e levantamento, proposição de temas, organização/produção de material, desenvolvimento das atividades e registro. As 30 horas de carga horária da PCC, do 1ํㅡㄴ ao $4^{\circ}$ semestre do $\mathrm{CPe}$, serão organizadas em: 8 horas para observação (em instituições de ensino preferencialmente públicas); 10 horas para elaboração de projetos, materiais e/ou minicursos; 4 horas para desenvolvimento das atividades; e 8 horas para sistematização e registro.

Nesse sentido, para Silvério (2017, p. 167):

No que se refere à PCC e à superação do mecanismo de transposição didática, como forma de transmissão unidirecional de um conteúdo disciplinar descontextualizado, é preciso um esforço didático para tornar as experiências mais reflexivas, buscando associá-las com as pesquisas sobre ensino das diversas especialidades das áreas de conhecimento relacionadas ao ensino, de tal forma que se a transposição didática for proposta como atividade, levará em conta os pré-requisitos apontados nessas investigações para o tratamento de determinado assunto ou conteúdo.

Em suma, o Parecer CNE/CP n. 9/2001 acrescenta que o planejamento dos cursos de formação de professores para a Educação Básica deve prever situações didáticas em diversas oportunidades diferentes, nas quais os futuros professores possam fazer uso do embasamento teórico, mobilizar outros conhecimentos e refletir sobre a prática. $O$ documento prevê que essas situações didáticas se deem em três momentos distintos: no interior de áreas ou disciplinas, em tempo e espaço curricular específico e no estágio supervisionado.

Educação \& Formação, Fortaleza, v. 4, n. 11, p. 142-160 maio/ago. 2019 
Os professores formadores são responsáveis não apenas pela disciplina de PPE, mas também por definir e constatar a(s) instituição(ões) pública(s) em que os(as) estudantes realizarão a PCC; por estabelecer como as atividades serão desenvolvidas (em equipes ou individualmente); por orientar os(as) discentes na elaboração das atividades; por acompanhar a aplicação das atividades propostas; por registrar as atividades desenvolvidas para composição de arquivo; e por entregar a documentação referente à PCC à coordenação do curso, com um registro completo da atividade realizada. Os licenciandos são responsáveis pelo desenvolvimento das atividades orientadas pelos professores e, ao final de semestre, por apresentar os registros da realização das atividades da PCC.

\section{O PERCURSO METODOLÓGICO}

A presente pesquisa se caracteriza como pesquisa de abordagem qualitativa. Considera-se que a empiria é tida no momento de construção teórica, em que, mediante pesquisa bibliográfica e análise documental, é analisada a constituição do conhecimento epistemológico na disciplina de Pesquisa e Processos Educativos, por meio da PCC, como prática pedagógica formativa que contribui para o desenvolvimento profissional dos futuros professores.

Para a geração dos dados, os pareceres, resoluções e normativas foram lidos e categorizados, buscando compreender nas análises evidenciadas a composição legal referente à PCC a partir de cada documento.

Dessa forma, conforme Pereira e Mohr (2017, p. 27), "[...] um parecer objetiva contextualizar, analisar, detalhar e justificar propostas legais, as quais geralmente são apresentadas ao final do documento ainda como sugestão". E "[...] as resoluções são instrumentos normativos jurídicos finalizados que instituem normas e procedimentos analisados e propostos nos pareceres" (PEREIRA; MOHR, 2017, p. 27).

Concomitantemente à realização da pesquisa bibliográfica, teve início a pesquisa documental do material selecionado previamente, a fim de alcançar os objetivos investigativos. Segundo Severino (2007), a pesquisa documental assemelha-se à pesquisa bibliográfica e utiliza como fonte documentos no sentido amplo, a partir dos quais o pesquisador desenvolve sua investigação e análise.

Educação \& Formação, Fortaleza, v. 4, n. 11, p. 142-160 maio/ago. 2019 
No que tange às técnicas e instrumentos que subsidiaram as análises do corpus documental escolhido, a presente pesquisa utilizou-se da técnica de análise de conteúdo para melhor compreensão dos dados coletados. Para Bardin (2009), a análise de conteúdo compreende um conjunto de técnicas destinadas à análise das comunicações. Não se trata de um instrumento, mas de um leque de apetrechos ou, com maior rigor, de um único instrumento, mas marcado por uma grande disparidade de formas e adaptável a um campo de aplicação muito vasto.

\section{DISCIPLINAS DE PESQUISA E PROCESSOS EDUCATIVOS E SUA INTER- -RELAÇÃO COM A PRÁTICA COMO COMPONENTE CURRICULAR}

Nesta seção, procurou-se analisar o núcleo de disciplinas integradoras do PPC do curso de Pedagogia do IFC, campus Camboriú, a fim de compreender a constituição de seu desenvolvimento curricular, mediante o uso de uma das três categorias de análise do estudo de Gatti e Barretto (2009), intitulado Professores do Brasil: impasses e desafios, que engloba três grandes núcleos: 1) estudos básicos, 2) aprofundamento e diversificação de estudos e 3) estudos integradores. Destacamos que, no presente estudo, nossas análises sobre a disciplina de PPE dizem respeito ao núcleo de estudos integradores.

Nesse sentido, o currículo do CPe do IFC, campus Camboriú, tem a base da sua organização em conformidade com o artigo 6ำ da Resolução das Diretrizes Curriculares Nacionais para o curso de graduação em Pedagogia, licenciatura (DCNCLPe) (BRASIL, 2006), que propõe que a estrutura do $\mathrm{CPe}$, respeitadas a diversidade nacional e a autonomia pedagógica das instituições, seja dividida em: i) Núcleo de Estudos Básicos (NBAS); ii) Núcleo de Aprofundamento e Diversificação de Estudos (Nade); e iii) Núcleo de Estudos Integradores (NEI).

As disciplinas que compõem o NEl referem-se às disciplinas de PPE, tal como expresso no Quadro 1:

Educação \& Formação, Fortaleza, v. 4, n. 11, p. 142-160 maio/ago. 2019 
Quadro 1 - Disciplinas do NEI do curso de licenciatura em Pedagogia do IFC, campus Camboriú

\begin{tabular}{|c|c|c|c|}
\hline Disciplinas/Ementa & $\begin{array}{c}\text { Carga } \\
\text { horária } \\
\text { semestral }\end{array}$ & Créditos & PCC \\
\hline $\begin{array}{l}\text { Pesquisa e Processos Educativos I } \\
\text { Ementa: tipos de conhecimento. Método científico. Produção } \\
\text { e socialização do conhecimento. Caracterização do campo } \\
\text { de pesquisa em educação. Trabalhos acadêmicos e normas } \\
\text { para apresentação - Associação Brasileira de Normas } \\
\text { Técnicas (ABNT). Inserção na pesquisa educacional em } \\
\text { campo de atuação profissional. }\end{array}$ & 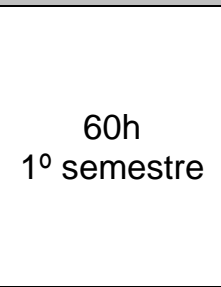 & 4 & 30 \\
\hline $\begin{array}{l}\text { Pesquisa e Processos Educativos II } \\
\text { Ementa: epistemologia da pesquisa em educação. Trajetória e } \\
\text { tendências da pesquisa em educação no Brasil. Aspectos } \\
\text { qualitativos e quantitativos da pesquisa, incluindo o estado do } \\
\text { conhecimento. Inserção no campo da pesquisa em educação. }\end{array}$ & 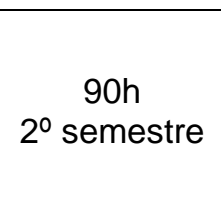 & 6 & 30 \\
\hline $\begin{array}{l}\text { Pesquisa e Processos Educativos III } \\
\text { Ementa: o sujeito pesquisador e os sujeitos da pesquisa em } \\
\text { educação. Inserção na realidade educacional em espaços } \\
\text { formais e não formais de educação. Procedimentos de } \\
\text { pesquisa em educação. }\end{array}$ & $\begin{array}{l}\text { 60h } \\
\text { 3o semestre }\end{array}$ & 4 & 30 \\
\hline $\begin{array}{l}\text { Pesquisa e Processos Educativos IV } \\
\text { Ementa: fundamentos para o planejamento da pesquisa em } \\
\text { educação. Inserção na realidade educacional em espaços } \\
\text { formais e não formais de educação. Sistematização da } \\
\text { pesquisa em educação. }\end{array}$ & $\begin{array}{l}\text { 60h } \\
\text { 4으 semestre }\end{array}$ & 4 & 30 \\
\hline $\begin{array}{l}\text { Pesquisa e Processos Educativos V } \\
\text { Ementa: fundamentos para o planejamento da pesquisa em } \\
\text { educação. A ética na pesquisa educacional. Sistematização } \\
\text { da pesquisa em educação. }\end{array}$ & $\begin{array}{l}\text { 60h } \\
\text { 5o semestre }\end{array}$ & 4 & 30 \\
\hline 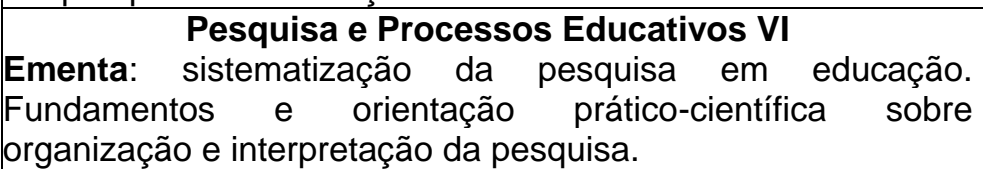 & $\begin{array}{l}\text { 60h } \\
6 \text { semestre }\end{array}$ & 4 & 30 \\
\hline $\begin{array}{l}\text { Pesquisa e Processos Educativos VII } \\
\text { Ementa: fundamentos e orientação prático-científica sobre } \\
\text { organização e interpretação, coleta e análise de dados da } \\
\text { pesquisa. Elaboração do Trabalho de Curso. }\end{array}$ & $\begin{array}{l}\text { 60h } \\
7^{\circ} \text { semestre }\end{array}$ & 4 & 30 \\
\hline $\begin{array}{c}\text { Pesquisa e Processos Educativos VIII } \\
\text { Ementa: finalização e defesa do Trabalho de Curso. }\end{array}$ & $\begin{array}{c}90 \mathrm{~h} \\
8 \text { semestre }\end{array}$ & 6 & 30 \\
\hline
\end{tabular}

Fonte: Adaptado pelas autoras da matriz curricular do curso de licenciatura em Pedagogia do IFC, campus Camboriú $(2011,2017)$.

Pela análise dos documentos (Projeto Pedagógico do Curso de Pedagogia; Regulamento da disciplina de Pesquisa e Processos Educativos (PPE) e Trabalho de Curso (TC); e Normatização da Prática como Componente Curricular - PCC), constatou-se que as disciplinas de PPE (de I a VIII) têm como objetivo desenvolver nos estudantes a capacidade investigativa e produtiva, contribuir para a sua formação básica, profissional, artística, científica e política, bem como para a sua inserção nos campos de investigação. São disciplinas que contribuem para a formação dos licenciandos nos 
eixos de formação do curso: Educação Infantil, Anos Iniciais, Modalidades da Educação, Gestão e Espaços não Escolares.

O Parecer CNE/CP n. 9/2001 determina que a proposição de situações didáticas por meio das PCCs deve ocorrer tanto nas disciplinas de conteúdos pedagógicos quanto nas disciplinas de conteúdo específico, em tempos e espaços específicos, que articulem as atividades práticas interdisciplinares, como a observação e a reflexão, com o registro de observações realizadas e a resolução de situações-problema existentes no cotidiano profissional do professor. As PCCs podem ser desenvolvidas no contexto escolar, mas não especificamente nele, pois a inserção na prática profissional pode ocorrer também por meio de filmes, vídeos, narrativas de professores, situações simuladas, estudos de caso, entre outras situações (BRASIL, 2002a).

Vale destacar que, no PPC do CLPe do IFC, campus Camboriú, as 400 horas de PCC estão distribuídas em várias disciplinas, especificamente nas de Fundamentos Metodológicos e, no objeto do presente estudo, nas disciplinas de Pesquisa e Processos Educativos, que transversalizam o curso do $1^{\circ}$ ao $8^{\circ}$ semestre, com atividades de PCC desde o início do percurso formativo. Assim, as disciplinas da PPE (de I a VIII), somadas, alcançam 240 horas, mais de $50 \%$ da carga horária exigida para a inserção dos estudantes na realidade escolar da Educação Básica e em espaços não formais.

Silvério (2017) considera que o licenciado, ao ser exposto a essa série de fatores que envolve a PCC, detendo, assim, um conhecimento mais abrangente sobre os aspectos que envolvem a prática docente, terá melhores condições de se aproximar da realidade da escola e da prática profissional, o que the proporcionará uma oportunidade de refletir acerca dos fundamentos de sua prática, a fim de desenvolver experiências mais significativas em seu estágio supervisionado.

Ao analisar a prática formativa interdisciplinar desenvolvida nas disciplinas de Pesquisa e Processos Educativos, tendo-se em vista as propostas de inter-relação entre os conhecimentos teóricos e práticos e a assunção da pesquisa como princípio educativo que Ihe são características, percebe-se uma preocupação com a inserção dos licenciandos na realidade social da Educação Básica e do campo educacional.

Em consequência, segundo Silvério (2017), a PCC assume um papel de suma importância na formação de professores, pois, por meio dessa prática pedagógica, os(as) licenciandos(as) podem vivenciar os desafios e possibilidades de serem professores(as),

Educação \& Formação, Fortaleza, v. 4, n. 11, p. 142-160 maio/ago. 2019

DOI: https://doi.org/10.25053/redufor.v4i11.319

http://seer.uece.br/redufor 
percebendo "[...] como se faz necessária e urgente a aproximação/integração ao mundo da escola, local onde todas as práticas formativas ganham finalidade e cumprem seu verdadeiro papel moral e ético" (SILVÉRIO, 2017, p. 167-168).

Com relação ao Núcleo de Estudos Integradores, as disciplinas de PPE, que verticalizam o currículo do $\mathrm{CPe}$, mostram que a formação dos estudantes tem como princípio o ensino com pesquisa, aspecto identificado após a análise de conteúdo das ementas e do documento Regulamento da disciplina de Pesquisa e Processos Educativos e Trabalho de Curso (TC) (IFC CAMBORIÚ, 2017c), que descreve e normatiza essa prática de ensino.

Nesse sentido, na afirmação de García (1999), muito se tem a reclamar de uma reforma das práticas de ensino por diferentes instâncias. Mas reformar as práticas de ensino por si só não é possível se não se atender a outras dimensões da formação inicial de professores e do sistema educativo, fazendo-se necessária uma revisão do currículo e dos programas de formação inicial, pois não há como se admitir a separação entre o conhecimento teórico e prático. É importante que as Instituições de Ensino Superior (IES) potencializem os conhecimentos pedagógicos em conjunto com os conhecimentos didáticos do conteúdo, para o desenvolvimento de um conhecimento didático do conteúdo de ensinar adquirido à medida que a prática e a teoria são aprendidas e aplicadas no contexto escolar.

Conforme 0 artigo $2^{\circ}$ do referido regulamento (IFC CAMBORIÚ, 2017c), as disciplinas de PPE têm como objetivos proporcionar formação com pesquisa, bem como inserir os licenciandos nos campos de atuação profissional desde o processo inicial de formação. Desse modo, procura desenvolver a capacidade investigativa do estudante e contribuir para a sua formação básica, profissional, artística, científica e política, o que, na nossa análise, traz contributos valiosos à formação inicial dos licenciados em Pedagogia.

Está-se de acordo com Silvério (2017, p. 167) no tocante à opinião de que é desejável e possível pensar que o contato dos discentes com as pesquisas sobre ensino e com temas relacionados à atuação profissional da docência "[...] pode oportunizar um envolvimento e uma prática de pesquisa posterior nesse campo da formação".

Analisando-se o regulamento (IFC CAMBORIÚ, 2017c), constata-se que a carga horária da PPE I (1ํㅗㄹ semestre) divide-se em 60 horas teóricas e 30 horas de PCC, havendo uma relação interdisciplinar entre ela e a disciplina Pedagogia e Profissão

Educação \& Formação, Fortaleza, v. 4, n. 11, p. 142-160 maio/ago. 2019

DOI: https://doi.org/10.25053/redufor.v4i11.319

http://seer.uece.br/redufor 
Docente ( $1^{\circ}$ semestre) com a proposição integrada de inserção, que se dá por intermédio da Metodologia da História de Vida e das Narrativas. As 30 horas de PCC são empregadas na experiência de ouvir, por meio de entrevistas e/ou questionários de pesquisa, sujeitos/professores em exercício, tomando-se por critério o tempo de profissão, de maneira que seja possível contemplar a atuação de três profissionais em diferentes estágios da carreira: no início, no meio e no final.

Para Pereira e Mohr (2017), a ideia da preparação para a prática docente não deve ocorrer somente ao final do curso, durante os estágios supervisionados, ela deve ser inserida ao longo de toda a formação, quando se está refletindo sobre a atividade profissional, ou seja, é de suma importância superar a ideia de que o estágio é reservado à prática, enquanto a sala de aula é reservada à teoria. Portanto, "[...] não se pode deixar somente para o futuro docente a tarefa de transpor o conhecimento sobre ensino e aprendizagem para a situação de ensino-aprendizagem, sem proporcionar possibilidades de reflexões coletivas em todo o processo de formação" (PEREIRA; MOHR, 2017, p. 28).

O movimento de articulação direta entre essas duas disciplinas "[...] tem a intenção de aproximar os estudantes da realidade da profissão e ao mesmo tempo possibilita a aprendizagem dos processos de pesquisa, como dos objetivos, dos instrumentos de coleta de dados, enfim, das facilidades e dificuldades da prática da pesquisa" (IFC CAMBORIÚ, 2017c, p. 4).

Esse entendimento é reafirmado por Imbernón (2011), quando ressalta que o processo de formação deve dotar os professores de conhecimentos, habilidades e atitudes para desenvolver profissionais reflexivos e investigadores. Nessa perspectiva, o eixo fundamental do currículo de formação de professor é o desenvolvimento da capacidade de refletir sobre a própria prática docente, com o objetivo de aprender a interpretar, compreender e refletir sobre a realidade social e sobre o exercício da docência.

A PPE /I (2ำ semestre) apresenta proposta de articulação com a disciplina Infância e Pedagogia, "[...] tendo como eixo a problematização da infância a partir da inserção nos campos, que ocorrerá preferencialmente nos Anos Iniciais e Educação Infantil" (IFC CAMBORIÚ, 2017c, p. 5). As 30 horas de PCC preveem inserção nos campos de formação (Anos Iniciais e Educação Infantil) e leitura de textos acadêmicos relacionados a práticas de ensino nessas áreas de atuação docente.

Educação \& Formação, Fortaleza, v. 4, n. 11, p. 142-160 maio/ago. 2019 
Na PPE III ( $3^{\circ}$ semestre), a articulação direta ocorre com a disciplina Teorias Educacionais e Curriculares, "[...] tendo como eixo a problematização a partir da inserção nos campos, que ocorrerá preferencialmente na Gestão, nas Modalidades da Educação e Espaços não Escolares" (IFC CAMBORIÚ, 2017c, p. 5). As 30 horas de PCC destinam-se à inserção nos campos de formação da gestão, nas modalidades da educação e em espaços não escolares, assim como à leitura de textos acadêmicos relacionados a práticas de gestão e de ensino nessas áreas de atuação docente. Ressalta-se "[...] a importância de considerar a relação dos cursos de formação de professores e as escolas como um processo de investigação e reflexão da prática docente" (BARBOSA; CASSIANI, 2017, p. 179).

Conforme Pereira e Mohr (2017), por meio do Parecer CNE/CP n. 9/2001, há a possibilidade de as propostas pedagógicas e curriculares dos cursos de formação de professores para a Educação Básica prever situações didáticas em diversas oportunidades diferentes, nas quais os futuros professores possam fazer uso do embasamento teórico, mobilizar outros conhecimentos e refletir sobre a prática. Também que essas "[...] situações didáticas sejam encontradas em três momentos distintos: no interior de áreas ou disciplinas, em tempo e espaço curricular específico e no estágio supervisionado" (PEREIRA; MOHR, 2017, p. 28).

Consoante o regulamento da disciplina de PPE (IFC CAMBORIÚ, 2017c), a proposição para o $2^{\circ}$ e o $3^{\circ}$ semestres da PPE prevê estudos sobre a trajetória e as tendências da pesquisa em educação no Brasil, sobre as abordagens qualitativas e quantitativas, sobre a prática de pesquisa e a realidade educacional/escolar, contemplando "[...] a aproximação e a identificação de temas e problemas de pesquisa na área educacional/escolar e não escolar, por meio da inserção na realidade educacional e em paralelo aos princípios para o planejamento da pesquisa em educação" (IFC CAMBORIÚ, 2017c, p. 4).

Como ponto relevante dessa proposição formativa organizada pelo Regulamento da Pesquisa como Principio Educativo (I a VIII), destaca-se a realização, no 2o e no $3^{\circ}$ semestres, de trabalhos coletivos como estudos de textos e avaliações compartilhadas entre as disciplinas.

Na PPE IV, ocorre a elaboração do projeto de pesquisa a partir da escolha de um tema e de um problema/questionamento de pesquisa. Ao tomar conhecimento dos 
modos com que o campo científico se instala na prática, na realidade, os acadêmicos têm a oportunidade de pesquisar, de levantar dúvidas, de elaborar as questões de pesquisa e de compreender um problema.

Uma prática de ensino que se destaca nessa disciplina, realizada mediante as aulas teóricas e a PCC, diz respeito à forma com que o trabalho de articulação entre pesquisa e inserção nas questões educacionais é organizado. Conforme o documento que regulamenta a prática da PPE (I a VII) (IFC CAMBORIÚ, 2017c), no início do 5o semestre do curso, os professores responsáveis pela disciplina promovem um encontro de socialização entre estudantes e docente, no qual são apresentados os projetos de pesquisas desenvolvidos pelos licenciandos, a fim de que recebam possíveis contribuições dos participantes.

O regulamento da PPE (IFC CAMBORIÚ, 2017c) garante que a disciplina seja ministrada por pelo menos dois professores graduados em Pedagogia e que, nessa prática pedagógica da PPE (I ao VII), haja o acompanhamento pedagógico integral dos estudantes ao longo de todo 0 itinerário formativo. Do $1^{0}$ ao $5^{\circ}$ semestre, esse acompanhamento é feito pelos mesmos professores da PPE; e do $6^{\circ}$ ao $8^{\circ}$ semestre, pelos professores da PPE e pelos orientadores, nos casos em que os acadêmicos optam por orientadores distintos dos professores da disciplina.

Conforme Imbernón (2011), quando atuam como pesquisadores, professores e futuros professores têm mais condições de decidir quando e como aplicar os resultados da pesquisa que estão realizando; sua experiência os ajuda a colaborar mais uns com os outros e, por fim, eles aprendem a ser profissionais melhores, tornando-se capazes de transcender o imediato, o individual e o concreto.

Segundo regulamento da PPE (IFC CAMBORIÚ, 2017c), nas disciplinas de PPE V, VI e VII (5ํ, $6^{\circ}$ e $7^{\circ}$ semestres), as vivências da prática da pesquisa, realizadas pelos professores responsáveis pela disciplina, devem se dar de forma mais contínua, intercalando momentos de aula e orientação individual e coletiva. Na PPE VIII, as análises dos dados da pesquisa são concluídas e o TC finalizado, o qual será posteriormente defendido em uma apresentação pública diante de uma banca. Destaca-se que toda a organização das defesas, a composição das bancas, os cronogramas e os documentos de registro são de responsabilidade dos professores da disciplina de PPE. 
No desenvolvimento da disciplina de PPE (do $1^{\circ}$ ao $8^{\circ}$ semestre), prevê-se que a elaboração do TC seja feita de forma articulada com os conhecimentos construídos ao longo das experiências formativas proporcionadas por esse componente do currículo, propondo-se, de forma crítica, uma análise dos processos realizados no decorrer da disciplina. Para Popkewitz (2001), compreende-se os significantes teoria e prática não em polos opostos e/ou contraditórios, mas como um par binário no qual os termos se constituem mutuamente.

Desse modo, pela análise dos documentos, foi possível identificar uma relação de proximidade entre as disciplinas pertinentes à pesquisa, à teoria e à prática curricular, principalmente porque a análise das ementas do PPC revelou a proposição de interseção entre esses conhecimentos desde o início do $\mathrm{CPe}$, visto que as disciplinas de PPE possuem a intenção de estabelecer a tríade entre ensino, pesquisa e extensão, em uma tentativa de aproximar e inter-relacionar os conteúdos das disciplinas de PPE (de I a VIII) com outras disciplinas do currículo do curso. Para Imbernón (2011), na formação inicial é importante introduzir metodologia que seja presidida pela pesquisa-ação, como processo fundamental para a aprendizagem da reflexão educativa, vinculando constantemente teoria e prática, com consciência crítica para o avanço dos processos educativos e da formação docente, de tal sorte que o próprio profissional da educação consiga encontrar alternativas para os problemas do ensino e do contexto escolar em conjunto com os demais profissionais das instituições educativas.

Nesse sentido, a partir de Pereira e Mohr (2017, p. 28):

\begin{abstract}
Pode-se observar que a ideia é de que a prática, ou a preparação para a prática docente, não deve ocorrer somente ao final do curso, durante os estágios supervisionados; ela deve ser inserida ao longo de toda a formação, quando se está refletindo sobre a atividade profissional. Com isso se quer superar a ideia de que o estágio é reservado à prática, enquanto a sala de aula é reservada à teoria [...].
\end{abstract}

Em suma, a proposição da transversalização das disciplinas de PPE ao longo de todo o $\mathrm{CPe}$ do IFC é uma prática pedagógica que merece um olhar mais detido, em razão de sua inter-relação com a PCC e a inserção dos licenciandos na realidade social, do primeiro ao último semestre do curso, pois a interação entre ensino, pesquisa, prática e conhecimentos do campo da profissão docente é elemento de primeira ordem. Porém, Moraes (2001) destaca que se precisa do cuidado necessário na implementação das 
novas políticas educacionais no Brasil, que buscam ampliar o espaço e a carga horária de prática docente, para não se ter um "recuo de teoria", ou seja, uma demasiada diminuição de conhecimentos teóricos necessários ao ensino.

\section{CONSIDERAÇÕES FINAIS}

Para que uma prática de ensino alcance os objetivos de um curso de formação de professores, propondo na formação dos licenciandos a aproximação e a vivência com o contexto social da educação, são necessários processos formativos como os realizados nas disciplinas de PPE, que contemplam em suas propostas a PCC, e uma ação de ensino e aprendizagem que fomenta a transformação da realidade escolar e aproximação da instituição formadora ao universo da Educação Básica.

Por isso, destaca-se a necessidade de avançar nas pesquisas sobre os desenhos curriculares dos cursos de licenciatura para a Educação Básica. O debate sobre a formação inicial do professor e do pedagogo tem mobilizado os profissionais da educação, bem como os gestores estaduais e municipais que respondem diretamente pelas escolas. A partir das reais necessidades de formação, é necessário criar condições para que os cursos de licenciatura possam responder às demandas do ensino e da aprendizagem da Educação Básica no país.

Em suma, destacamos que as análises desenvolvidas neste estudo trazem uma oportunidade de diálogo com os pesquisadores do campo da formação de professores, em especial aos que se dedicam a pesquisar a formação inicial de professores proposta pelos desenhos curriculares (das matrizes curriculares) dos $\mathrm{CPe}$ do Brasil, além de representarem uma contribuição para as experiências de currículo e práticas de ensino do campo das licenciaturas.

\section{REFERÊNCIAS}

ANDRÉ, M. (Org.). O papel da pesquisa na formação e na prática dos professores. Campinas: Papirus, 2012.

BARBOSA, A. T.; CASSIANI, S. A Prática como Componente Curricular em um curso de formação de professores de Biologia: sentidos e possibilidades. In: MOHR, A.; 
WIELEWICKI, H. G. (Org.). Prática como Componente Curricular: que novidade é essa 15 anos depois? Florianópolis: NUP/CED, 2017. p. 171-192.

BARDIN, L. Análise de conteúdo. Lisboa: 70, 2009.

BRASIL. Conselho Nacional de Educação. Resolução n. 2, de 1ำ de julho de 2015. Define as Diretrizes Curriculares Nacionais para a formação inicial em nível superior (cursos de licenciatura, cursos de formação pedagógica para graduados e cursos de segunda licenciatura) e para a formação continuada. Diário Oficial [da] República Federativa do Brasil, Poder Executivo, Brasília, DF, 2 jul. 2015.

BRASIL. Ministério da Educação. Conselho Nacional de Educação. Parecer CNE/CP n. 9, de 8 de maio de 2001. Diretrizes Curriculares Nacionais para a Formação de Professores da Educação Básica, em nível superior, curso de licenciatura, de graduação plena. Diário Oficial [da] República Federativa do Brasil, Poder Executivo, Brasília, DF, 18 jan. 2002a.

BRASIL. Ministério da Educação. Conselho Nacional de Educação. Parecer CNE/CP n. 28, de 2 de outubro de 2001. Dá nova redação ao Parecer CNE/CP n. 21/2001, que estabelece a duração e a carga horária dos cursos de Formação de Professores da Educação Básica, em nível superior, curso de licenciatura, de graduação plena. Diário Oficial [da] República Federativa do Brasil, Poder Executivo, Brasília, DF, 18 jan. 2002b.

BRASIL. Ministério da Educação. Conselho Nacional de Educação. Parecer CNE/CP n. 1, de 18 de fevereiro de 2002. Institui Diretrizes Curriculares Nacionais para a Formação de Professores de Educação Básica, em nível superior, curso de licenciatura, de graduação plena. Diário Oficial [da] República Federativa do Brasil, Poder Executivo, Brasília, DF, 9 abr. 2002c.

BRASIL. Ministério da Educação. Conselho Nacional de Educação. Resolução CNE/CP n. 2, de 19 de fevereiro de 2002. Institui a duração e a carga horária dos cursos de licenciatura, de graduação plena, de formação de professores da Educação Básica em nível superior. Diário Oficial [da] República Federativa do Brasil, Poder Executivo, Brasília, DF, 4 mar. 2002d.

BRASIL. Resolução CNE/CP n. 1, de 15 de maio de 2006. Institui Diretrizes Curriculares Nacionais para o curso de graduação em Pedagogia, licenciatura. Diário Oficial [da] República Federativa do Brasil, Poder Executivo, Brasília, DF, 16 maio 2006.

GARCÍA, C. M. Desenvolvimento profissional: passado e futuro. Sísifo: Revista das Ciências da Educação, Lisboa, n. 8, p. 7-22, 2009.

GATTI, B. A. O curso de licenciatura em Pedagogia: dilemas e convergências. EntreVer, Florianópolis, v. 2, n. 3, p. 151-169, 2012.

GATTI, B. A.; BARRETTO, E. S. S. Professores do Brasil: impasses e desafios. Brasília, DF: Unesco, 2009. 
IFC - Instituto Federal Catarinense. Campus Camboriú. Normatização da Prática como Componente Curricular (2011). Camboriú: IFC, 2017a. Mimeografado.

IFC - Instituto Federal Catarinense. Campus Camboriú. Projeto pedagógico do curso de licenciatura em Pedagogia. Camboriú: IFC, 2017b. Mimeografado.

IFC - Instituto Federal Catarinense. Campus Camboriú. Regulamento da disciplina de Pesquisa e Processos Educativos e Trabalho de Curso - TC (2017). Camboriú: IFC, 2017c. Mimeografado.

IMBERNÓN, F. Formação docente e profissional. São Paulo: Cortez, 2011.

MORAES, M. C. M. Recuo da teoria: dilemas na pesquisa em educação. Revista Portuguesa de Educação, Braga, v. 14, n. 1, p. 7-25, 2001.

OLIVEIRA, M. C. A.; BRITO, L. D. Por entre as palmas desse lugar... A Prática como Componente Curricular dos cursos de licenciatura em Ciências Biológicas de duas universidades estaduais do Nordeste. In: MOHR, A.; WIELEWICKI, H. G. (Org.). Prática como componente curricular: que novidade é essa 15 anos depois? Florianópolis: NUP/CED, 2017. p. 87-106.

PEREIRA, B.; MOHR, A. A Prática como Componente Curricular na perspectiva de professores universitários de Ciências Biológicas da Universidade Federal de Santa Catarina. In: MOHR, A.; WIELEWICKI, H. G. (Org.). Prática como componente curricular: que novidade é essa 15 anos depois? Florianópolis: NUP/CED, 2017. p. 193-210.

POPKEWITZ, T. Lutando em defesa da alma: a política do ensino e a construção do professor. Porto Alegre: Artmed, 2001.

SCHEIBE, L. Formação de professores e pedagogos na perspectiva da LDB. In: BARBOSA, R. L. L. (Org.). Formação de educadores: desafios e perspectivas. São Paulo: Unesp, 2003. p. 171-183.

SEVERINO, A. J. Metodologia do trabalho científico. 23. ed. São Paulo: Cortez, 2007.

SILVÉRIO, L. E. R. Prática como componente curricular: desafios e possibilidades da integração da formação acadêmica com o campo profissional da docência. In: MOHR, A.; WIELEWICKI, H. G. (Org.). Prática como componente curricular: que novidade é essa 15 anos depois? Florianópolis: NUP/CED, 2017. p. 151-170.

SOARES, M. As pesquisas nas áreas específicas influenciando o curso de formação de professores. In: ANDRÉ, M. (Org.). O papel da pesquisa na formação e na prática dos professores. Campinas: Papirus, 2012. p. 91-105.

TORRES, J. R.; SILVÉRIO, L. E. R.; MAESTRELLI, S. R. P. A Prática como Componente Curricular no curso de graduação de Ciências Biológicas da UFSC: um diagnóstico inicial. In: MOHR, A.; WIELEWICKI, H. G. (Org.). Prática como componente curricular. que novidade é essa 15 anos depois? Florianópolis: NUP/CED, 2017. p. 211-242.

Educação \& Formação, Fortaleza, v. 4, n. 11, p. 142-160 maio/ago. 2019

DOI: https://doi.org/10.25053/redufor.v4i11.319

http://seer.uece.br/redufor 


\section{Andressa Graziele Brandt (Brasil, Santa Catarina, Camboriú) - Instituto Federal de Educação,} Ciência e Tecnologia Catarinense (IFC)

Doutora em Educação pela UFSC. Membro do Grupo de Estudos e Pesquisas: Formação de Professores e Práticas de Ensino (Foppe). Supervisora educacional do IFC. Professora da área de Pedagogia do IFC, campus Camboriú.

Lattes: <http://lattes.cnpq.br/5766947022430917>.

E-mail: <andressabrandt@hotmail.com>.

\section{Márcia de Souza Hobold (Brasil, Santa Catarina, Florianópolis) - Universidade Federal de Santa Catarina (UFSC)}

Pós-Doutora em Educação pela Pontifícia Universidade Católica de São Paulo (PUC-SP). Integra o Núcleo de Pesquisa sobre o Desenvolvimento Profissional dos Professores do Programa de Educação: Psicologia da Educação da PUC-SP. Coordena o Grupo de Estudos e Pesquisa: Formação de Professores e Práticas de Ensino (Foppe). Integra a Rede Interinstitucional de Pesquisas sobre a Formação e as Práticas Docentes (Ripefor). Professora efetiva de Didática do Departamento de Metodologia de Ensino e do Programa de Pós-Graduação em Educação do Centro de Ciências da Educação da UFSC.

Lattes: <http://lattes.cnpq.br/4242212112799297>.

E-mail: <marcia.hobold@ufsc.edu.br>. 